\title{
Um diálogo possível: paralelo entre Infância e história: destruição da experiência e origem da história, de Giorgio Agamben, e o processo de criação de Peças curtas para desesquecer, da Companhia Perdida
}

Flávia Scheye Spirópulos ${ }^{1}$

\section{Resumo}

Este artigo é resultado de pesquisa realizada no Programa de Pós-Graduação em Artes Cênicas (ECA-USP) e relaciona o texto Infância e História: Destruição da Experiência e Origem da História, de Giorgio Agamben (2008), ao processo de criação da obra Peças curtas para desesquecer, da Companhia Perdida, com direção de Juliana Moraes (2012). Partindo do pressuposto de que arte é forma de conhecimento que comunica por meio da materialidade do corpo (VIEIRA, 2006, 2008), o estudo considera a criação em dança como produção de linguagem e aproxima momentos vividos pelas intérpretes da companhia aos conceitos elaborados pelo autor acima citado.

Palavras-chave: dança, experiência, Giorgio Agamben, Companhia Perdida, Juliana Moraes.

\section{Abstract}

This article is the result of research conducted in the Programa de Pós-Graduação em Artes Cênicas da ECA-USP (Posgraduate Program in Performing Arts of ECA-USP), and relates the text Infancy and History: Essays on the Destruction of Experience, by Giorgio Agamben (2008), to the process of dance creation of Peças curtas para desesquecer (Short pieces to unforget), of Companhia Perdida (Perdida Dance Company), directed by Juliana Moraes (2012). Assuming that art is a form of knowledge that communicates through the materiality of the body (VIEIRA, 2006, 2008), the study considers the creation of dance as language production and close moments experienced by interpreters of the company to the concepts developed by the author above.

Keywords: dance, experience, Giorgio Agamben, Companhia Perdida, Juliana Moraes.

\section{Resumen}

Este artículo es el resultado de una investigación realizada en el Programa de Pós-Graduação em Artes Cênicas de ECA-USP (Programa de Postgrado en Artes Escénicas de ECA-USP) y se refiere al texto Infancia e historia. Destrucción de la experiencia y origen de la historia, de Giorgio Agamben (2008), y el proceso de creación de la obra Peças curtas para desesquecer (Piezas breves para no olvidar), da Companhia Perdida (Compañía de Danza Perdió), con dirección de Juliana Moraes (2012). En el supuesto que el arte es una forma de conocimiento que se comunica através de la materialidad del cuerpo (VIEIRA, 2006, 2008), el estudio considera la creación de la danza como lenguaje producción y llegando a momentos experimentados por los intérpretes de la compañía a los conceptos desarrollados por el autor antes citado.

Keywords: danza, experiencia, Giorgio Agamben, Companhia Perdida, Juliana Moraes.

\footnotetext{
1 É mestranda no Programa de Pós-Graduação em Artes Cênicas, na Escola de Comunicação e Artes da Universidade de São Paulo (ECA-USP). Sua pesquisa de mestrado está em andamento desde 2012, sob a orientação da Profa. Dra. Maria Helena Franco de Araújo Bastos, na área de Teoria e Prática do Teatro - Texto e Cena. Desde o início de 2013, recebe apoio da CAPES. Flávia é bailarina e pesquisadora do corpo, integrante da Companhia Perdida (dirigida por Juliana Moraes) e professora de dança.
} 


\section{Introdução}

Giorgio Agamben (2008) dá início ao seu Ensaio Sobre a Destruição da Experiência, em Infância e História: Destruição da Experiência e Origem da História, afirmando que:

Todo discurso sobre a experiência deve partir atualmente da constatação de que ela não é mais algo que ainda nos seja dado fazer. Pois assim como foi privado da sua biografia, o homem contemporâneo foi expropriado de sua experiência: aliás, a incapacidade de fazer e transmitir experiências talvez seja um dos poucos dados certos de que disponha sobre si mesmo (AGAMBEN, 2008, p. 21-22).

O autor identifica as raízes da "pobreza de experiência" nas guerras mundiais pelas quais a humanidade passou; porém, explicita que, hoje, sem a necessidade de uma catástrofe, é a própria existência cotidiana que não se torna passível de tradução em experiência pelo homem.

Até o século XIX, eram justamente as trocas do dia a dia a serem compreendidas como experiência e transmitidas às seguintes gerações com base no crédito à autoridade daquele que a contava. Segundo o autor, hoje acontece o oposto: com a banalidade do cotidiano que vivemos, a autoridade do conto foi desautorizada pelos slogans e preferimos nos esconder atrás de lentes de máquinas fotográficas e filmadoras, assegurando-nos de que as experiências que possam existir no mundo fiquem à parte do nosso contato.

Como autora deste estudo, nascida no final do século XX, em 1981, propus-me, há mais ou menos uma década, a fazer dança, acreditando que, por seu intermédio, seja possível não só vivenciar, mas também proporcionar experiências. Em outubro de 2012 estreei junto à Companhia Perdida (grupo de dança contemporânea, dirigido por Juliana Moraes ${ }^{2}$, do qual faço parte como criadora-intérprete) o trabalho Peças curtas para desesquecer, como resultado de uma pesquisa que durou 18 meses.

A ideia deste artigo é, então, traçar um diálogo entre este processo de criação e o texto de Agamben, torcendo para que, no desenrolar da discussão, surjam brechas a partir das quais seja possível alimentar o desejo - que acredito compartilhar com outros artistas de minha geração - de que a arte permaneça como uma forma de conhecimento que elabore possíveis alternativas à realidade descrita acima.

2 Juliana Moraes é bailarina, coreógrafa e professora. Doutora em Artes pela UNICAMP, mestre e especialista em Dança pelo Laban Centre, de Londres, e bacharel em dança pela UNICAMP. Dirige a Companhia Perdida desde 2008. 


\section{Percursos e descobertas: "Viver é muito perigoso"3}

Em 2011, a Companhia Perdida iniciou um trabalho intitulado "Sensorimemórias". A ideia era investigar a intrincada construção sensorial do corpo a partir de experiências passadas que mantivessem forte impressão na memória das intérpretes da companhia. Peças curtas para desesquecer foi o resultado cênico dessa pesquisa. Ao invés de um espetáculo único, a obra se constitui de uma série composta por oito peças curtas, de 10 a 20 minutos de duração cada. São cinco solos, um de cada participante do projeto (Carolina Callegaro, Érica Tessarolo, Flávia Scheye, Isabel Monteiro e Juliana Moraes), além de um dueto, um trio e um quarteto.

Começamos o processo com cada intérprete fazendo descrições, na linguagem escrita, de lembranças particulares que reconhecíamos como sendo correspondentes a uma "sensorimemória"4. Nossa vontade era tentar reproduzir a sensação vivida por meio da construção de situações fictícias que simulassem os efeitos cinéticos da lembrança em nosso corpo.

Ao entrar em contato com a proposta da Profa. Dra. Ana Terra ${ }^{5}$, convidada a ministrar um workshop baseado no trabalho com objetos relacionais da artista plástica Lygia Clark (1920-1988), pudemos, finalmente, levantar algum material corporal que nos interessou. Foi do contato do corpo com objetos ordinários que surgiram as primeiras movimentações que se relacionavam com o que estávamos pesquisando. No artigo Reflexões sobre o processo de criação de estudos para Sensorimemórias, disponível no e-book ${ }^{6}$ Sensorimemórias: um processo de criação da Companhia Perdida, Juliana Moraes reconhece a qualidade das propostas de Ana Terra e diz que: "seguindo os procedimentos desse exercício, a experiência mobiliza o corpo para além da representação: ele não quer ser/fazer algo, ele simplesmente é" (MORAES, 2012, p.47).

Durante o processo, percebemos o quanto a proposta original era ingênua. Seria impossível viver uma experiência buscando, para isso, ignições que estavam fora do nosso corpo, em uma folha de papel.

3 Citação livre a João Guimarães Rosa (2001).

$4 \mathrm{O}$ termo 'sensorimemória' foi criado por Juliana Moraes para falar de experiências passadas que se inscreveram fortemente no corpo e reorganizaram sua estrutura. A partir deste termo, a Companhia Perdida iniciou sua pesquisa prática e entendeu que "sensorimemórias" constituem uma espécie de rememoração que transita entre sensação, memória e movimento.

5 Ana Terra é artista da dança, socióloga (FFLCH/USP), mestre em Artes (IA/UNICAMP) e doutora pela Faculdade de Educação (UNICAMP), onde desenvolveu pesquisa sobre as relações entre a dança e a educação somática.

6 O livro eletrônico pode ser acessado pelo site da companhia no endereço: www.companhiaperdida.com.br. 
Segundo Agamben,

A ideia de uma experiência separada do conhecimento tornou-se para nós tão estranha a ponto de esquecermos que, até o nascimento da ciência moderna, experiência e ciência possuíam cada uma seu lugar próprio. E não só: distintos também eram os sujeitos de que lançavam mão (AGAMBEN, 2008, p.26).

Como herança do pensamento moderno ocidental, ficou o desejo pela certeza, pela comprovação através do método, o que, segundo o autor, uniu experiência e conhecimento em um único sujeito absoluto: primeiramente o ego cogito cartesiano (a consciência), seguido de seu desdobramento no sujeito transcendental kantiano. Tal transformação no conceito de sujeito reverberou e transformou outros conceitos diretamente relacionados a essa concepção; dessa forma, as noções de experiência, conhecimento, processo etc., também foram, necessariamente, ressignificadas:

\begin{abstract}
A transformação de seu sujeito não deixa imutável a experiência tradicional. Enquanto o seu fim era de conduzir o homem à maturidade, ou seja, a uma antecipação da morte como ideia de uma totalidade consumada da experiência, ela era de fato algo de essencialmente finito, e logo, era algo que se podia "ter" e não somente "fazer". Mas uma vez referida ao sujeito da ciência, que não pode atingir a maturidade, mas apenas acrescer seus próprios conhecimentos, a experiência tornar-se-á, ao contrário, algo de essencialmente infinito, um conceito <assintótico>, como dirá Kant, ou seja, algo que se pode somente "fazer" e jamais "ter": nada mais, precisamente, do que o processo infinito do conhecimento. (AGAMBEN, 2008, p.32- 33).
\end{abstract}

De acordo com Agamben (2008), depois que Descartes concebeu o ego cogito, a proposição kantiana irá refutar tal sujeito absoluto cartesiano separando, novamente, "'eu penso', sujeito transcendental que não pode de modo algum ser substancializado ou psicologizado, da consciência psicológica ou 'eu empírico"' (AGAMBEN, 2008, p.40). Para Kant, o sujeito transcendental é incapaz de conhecer um objeto por si, precisa da intuição fornecida pela experiência sensível. A consciência, somente capaz de pensar, não pode, de fato, conhecer, uma vez que é mera representação.

Porém, com os pós-kantianos, os sujeitos transcendental e empírico se reunificam em um sujeito absoluto em um processo que se realiza de forma dialética: a consciência, capaz de conhecer (sujeito), se reconhece enquanto sujeito (objeto de conhecimento). O caminho para ciência se torna a própria ciência: "ciência da experiência da consciência" (AGAMBEN, 2008, p. 42). O sujeito/consciência está totalmente implicado na estrutura dialética.

No fim do século XIX, Dilthey propõe a ideia de Erlebnis (experiência vivida) (AGAMBEN, 2008). Dessa experiência, que tem origem no interior do sujeito, algo transparece; como uma árvore, da qual vemos o tronco e as folhagens, mas não suas 
raízes, ou a inspiração de um escritor, da qual só vemos a escrita. Para essa corrente, então, a experiência só se torna acessível quando se revela. Husserl tenta restaurar na "corrente dos Erlebnisse" uma experiência transcendental do eu cartesiano. Se o início é a experiência pura (que é "muda”), sua primeira expressão é em relação ao próprio sentido da consciência do ego cogito cartesiano.

É sobre este pano de fundo, que implica e transforma as relações entre os conceitos de experiência, consciência e sujeito, que Agamben formula sua questão sobre a infância da experiência:

\begin{abstract}
Talvez o fato de que, neste trecho, o sujeito transcendental seja apreendido imediatamente como uma expressão, ou seja, como algo de linguístico, não seja casual e permita pormos em questão tanto a fundação cartesiana da certeza do ego cogito em um pronuntiatium, quanto a identificação, por Dilthey, do Erlebnis com sua expressão. Uma teoria da experiência que desejasse verdadeiramente colocar de modo radical o problema do próprio dado originário deveria obrigatoriamente partir da experiência $<$ por assim dizer ainda muda $>$ (situada aquém daquela <expressão primeira>), ou seja, deveria necessariamente indagar: existe uma experiência muda, existe uma in-fância da experiência? $\mathrm{E}$ se existe, qual a sua relação com a linguagem? (AGAMBEN, 2008, p. 48).
\end{abstract}

Voltando ao processo de criação de "Peças curtas para desesquecer", depois do intenso fluxo de movimentação despertado com o trabalho da Ana Terra, a ação que se seguiu no processo de criação da Companhia Perdida foi justamente a de não agir.

Tivemos a oportunidade de realizar um segundo workshop, desta vez com o ator e preparador de intérpretes Gustavo Sol7. Sua instrução primeira era para que deitássemos no chão e, simplesmente, não fizéssemos nada. Ficávamos muito tempo ali, entregues ao silêncio e à quietude, até que pudéssemos desistir de fazer qualquer coisa, abrir mão da vontade de produzir. Sobre este trabalho, Juliana Moraes assinala:

A desistência derivada da distensão do tempo da espera desmonta as expectativas do corpo e faz com que ele mergulhe no tempo presente. Gustavo acredita que, após atingir esse estado, o corpo deixa de buscar a representação pura e se abre para a experiência investigativa (MORAES, 2012, p. 52).

Era neste momento que Gustavo intervinha novamente, sugerindo que passássemos a nos mover com foco na relação entre a voz e o movimento: percebendo que, para a emissão da voz, o aparelho fonador constrói diversos apoios no corpo; nós entrávamos em coordenação de movimento a partir da pressão que o ar exerce dentro do corpo e sua ressonância no espaço. Num turbilhão de sensações, aquele corpo/ voz se descobria enquanto ser.

7 Gustavo Sol é doutorando em Artes Cênicas (USP), Bacharel em Teatro (UNICAMP) e Mestre em Semiótica (PUC/SP, 2008). 
Um último workshop foi realizado pela companhia, desta vez, ministrado por Antônio Januzeli (Janô). $O$ trabalho foi construído em torno de poucas perguntas profundas: "Quem é o Ator/Bailarino?", "Qual a diferença entre o Ator/Bailarino e o Homem?", "Como se dá a passagem entre o Ator/ Bailarino e o Homem?". Com suas propostas, começamos a entender os limites daquela dança que estávamos produzindo, e pleitear que, com um trabalho de presença cênica elaborado, os materiais corporais poderiam tomar a forma de um discurso pessoal de cada intérprete.

\section{A experiência do limite}

Em um momento de seu texto, Agamben (2008) traça um diálogo entre dois relatos (o primeiro de Montaigne, presente em seus Essais, e outro de Rousseau, Rêveries du promeneur solitaire, escrito 200 anos depois do de Montaigne) que tratam de experiências que ocorrem em situações de liminaridade (estado entre sono/vigília ou vida/morte) nas quais, por vezes, ocorrem movimentos involuntários. Diz o autor:

\footnotetext{
Existem, portanto, certas experiências que não nos pertencem, que não podemos dizer <nossas>, mas que, justamente por isso, porque são, precisamente, experiências do inexperienciável, constituem o limite último ao qual pode lançar-se nossa experiência em sua tensão para a morte (AGAMBEN, 2008, p.50).
}

Tal ideia de liminaridade constituirá a noção de inconsciente que entra em vigor a partir do século XIX, conceito que, segundo o autor, será a evidência máxima da crise do problema da experiência moderna, fundada em cima do sujeito cartesiano, de forma a se tornar possível decifrar as características de uma nova experiência.

Considero que, em seu processo de criação, as intérpretes da Companhia Perdida passaram também por experiências de limite. Tanto o workshop de Ana Terra como o de Gustavo Sol incitaram nossos corpos a construir fortes impressões sensoriais, num turbilhão de sensações em que as movimentações eram, por vezes, resultado de escolhas conscientes, outras vezes, tomadas por catarse. Juliana Moraes reflete a esse respeito, definindo esse limiar como sendo uma característica das "sensorimemórias":

Os exemplos de sensorimemórias encontradas são muitos, e quase todos acabaram por se revelar inicialmente impensáveis, e até mesmo inacessíveis para as intérpretes da Companhia antes dos experimentos com os objetos relacionais através do método Clark/Terra. [...] Notamos que quando uma sensorimemória vem à tona, ela toma forma no corpo, num processo no qual o inconsciente sobe à consciência e se materializa fisicamente. Nesses momentos, o corpo se abre e é tomado, de maneira que a sensorimemória se revela, inclusive para quem a está lembrando, pelo e no corpo. [...] Em alguns casos, mesmo com todas as anotações, a movimentação nunca conseguiu ser recuperada. Por exemplo, ao ser tocada por um conduíte, Flávia Scheye deslocou-se diretamente para a lembrança de estar num lago 
quando criança e as histórias sobre cobras que os adultos contavam para que ela tivesse medo de entrar sozinha na água. Terminado o exercício, Flávia se recordava com precisão da memória infantil, mas não fazia a menor ideia de como havia se movido durante os últimos 30 minutos. Ela se movimentou loucamente, mudou de níveis e explorou combinações muito interessantes de diferentes partes do corpo curvando-se em direções díspares ao mesmo tempo - mas toda a movimentação se deu no completo esquecimento (MORAES, 2012, p. 49-51).

Eu também, em depoimento pessoal inserido no e-book da companhia, cheguei a comentar que:

Muitas vezes, a impressão que tenho é que as sensações que esta dança desperta em mim já estavam há tempos impressas no meu corpo, se mostrando, às vezes, quando encontravam alguma experiência que Ihes cabia (SCHEYE, 2012, p.114).

Ainda, para Marcelo Moreschi ${ }^{8}$, que acompanhou o processo conduzindo diálogos com conceitos e teorias relacionadas ao assunto:

Somos cúmplices de uma dramaturgia reveladora de algo muito arcaico, antigo e secreto que estava em estado dormente, inacessível. É uma dança acontecimento que questiona até que ponto conhecemos a nós mesmos, aquilo que está na própria intimidade de nosso ser-corpo (MORESCHI, 2012).

\section{A criação de um discurso}

De acordo com Agamben, o problema da experiência deve, necessariamente, deparar-se com o problema da linguagem. Considerando essa relação, o autor irá articular sua Teoria da Infância a partir da ideia de que a subjetividade seria a "capacidade do locutor de pôr-se como ego" (BENVENISTE apud AGAMBEN, 2008, p. 56).

Dizer "eu", é, assim, uma ação de discurso individual e singular que diz respeito ao próprio locutor: "O sujeito transcendental não é outro senão o 'locutor', e o pensamento moderno erigiu-se sobre esta assunção não declarada do sujeito da linguagem como fundamento da experiência e do conhecimento" (AGAMBEN, 2008, p.57).

Essa questão implica a necessidade de rever o sujeito transcendental kantiano, pois, se "eu penso" refere-se unicamente ao linguístico, apreender o sujeito, o próprio locutor, seria uma empreitada impossível, uma vez que, enquanto palavra, o sujeito já se encontra, de partida, expropriado de sua experiência pura ("muda"). A origem

\footnotetext{
8 Marcelo Moreschi possui graduação em Letras (Bacharelado, 1999; Licenciatura, 2000) e mestrado em Teoria e História Literária (2004) pela Universidade Estadual de Campinas. Possui doutorado em Línguas e Literaturas Hispânicas (com ênfase em Literatura Luso-brasileira) pela Universidade da Califórnia, Santa Barbara, EUA (2010). Atualmente, conduz pesquisa de pós-doutorado a respeito da obra de Flávio de Carvalho na Universidade Estadual de Campinas.
} 
da experiência seria, dessa forma, anterior ao sujeito e sua infância; como limitadora dessas instâncias, deveria existir anteriormente à linguagem: "in-fância".

Todavia, se a linguagem constitui a expressão humana, e se a consciência é seu sujeito, sua infância não deve existir antes ou independentemente da linguagem. A infância é justamente a origem da linguagem, ao mesmo tempo em que a linguagem é seu limite. Neste movimento circular, diz o autor, podemos buscar a ideia de experiência enquanto infância do homem:

Pois a experiência, a infância que aqui está em questão, não pode ser
simplesmente algo que precede cronologicamente a linguagem e que,
a uma certa altura, cessa de existir para versar-se na palavra, não é um
paraíso que, em um determinado momento, abandonamos para sempre a
fim de falar, mas coexiste originalmente com a linguagem, constitui-se aliás
ela mesma na expropriação que a linguagem dela efetua, produzindo a cada
vez o homem como sujeito (AGAMBEN, 2008, p. 59).

Se homem e linguagem estão imbricados em sua existência, devemos, então, diz o autor, deixar de lado a procura por uma origem do homem separado da linguagem (ou da linguagem separada do homem), pois não existe tal separação cronológica. Homem/linguagem não tem origem, sua história é dada por este encontro:

\begin{abstract}
Ela(origem dalinguagem) se situa em um ponto de coincidência entre diacronia e sincronia, no qual, como estado da língua não atestado historicamente, como <língua jamais falada > e, todavia real, ela garante a inteligibilidade da história linguística e, simultaneamente, a coerência sincrônica do sistema. Uma tal origem não poderá jamais resolver-se completamente em <fatos> que se possam supor historicamente acontecidos, mas é algo que ainda não cessou de acontecer. Poderíamos definir uma tal dimensão como a de uma "história transcendental", que constitui, em um certo sentido, o limite e a estrutura a priori de todo conhecimento histórico. (AGAMBEN, 2008, p. 61-62).
\end{abstract}

Infância, experiência e linguagem são conceitos enredados, coexistentes em sua história: "Como infância do homem, a experiência é a simples diferença entre humano e linguístico. Que o homem não seja já sempre falante, que ele tenha sido e seja ainda in-fante, isto é a experiência" (AGAMBEN, 2008, p.62).

Diferentemente da dos outros animais, a linguagem humana se caracteriza por um fenômeno de cisão entre língua e discurso. Somente quando o homem diz "eu" e se identifica como sujeito há uma apropriação da linguagem que se torna, então, um discurso.

Para entender essa passagem, o autor recorre a Benveniste, que distingue dois modos de significação: o primeiro, semiótico, diz respeito ao signo, ao reconhecível; é a identidade da coisa em si e alteridade em relação aos demais. O segundo, semântico, diz respeito ao discurso e, por isso, demanda uma ação de compreender: é quando a língua produz mensagens, é um sistema de signos que comporta um sentido. 
Para Agamben (2008), a infância seria o processo de passagem de uma instância à outra. Semiótico e semântico são limites que definem a infância do homem (ao mesmo tempo em que são definidos por ela). Este trânsito é a história do homem.

Neste sentido, as peças, principalmente os solos de Peças curtas para desesquecer, são, sem dúvida, a apropriação de um discurso de cada uma de nós, intérpretes-criadoras.

A maneira como cada bailarina organizou suas texturas de movimento foi tomando forma aos poucos, a partir de escolhas sempre discutidas e elaboradas em grupo. Se considerarmos coreografia como escrita de movimentos no tempo-espaço da cena, os estudos solos acabaram por se tornar depoimentos sobre como cada criadora-intérprete pensa coreografia. Neles, vê-se a mão da direção como aquilo que sustenta, encaminha e se responsabiliza pelos caminhos que foram surgindo. Nossos estudos iniciam uma disposição dentro do grupo para falar sobre nós mesmas, sem personagens ou figuras cênicas que nos protejam da exposição direta. São nossas memórias e experiências mais profundas que tomam forma e que talvez, justamente por serem tão singulares, sejam também coletivas (MORAES, 2012, p. 64-65).

Apesar da grande dificuldade de tentar traduzir em palavras (necessárias para as trocas ao longo do processo) as singularidades da dança que estávamos gerindo, tínhamos a clareza de que, ao mergulhar na pesquisa, o tipo de investigação sobre a qual estávamos nos debruçando mobilizava cada intérprete em seu íntimo, e, particularmente, muitas vezes eu achava difícil/estranho/doloroso me reconhecer ali.

Sobre meu solo, pude afirmar:

Tive que aprender a lidar com um solo que tem poucas variações dinâmicas a fim de não deixá-lo monótono e bobo; meu trabalho foi principalmente encontrar o tempo das coisas, não ficar ansiosa nas transições entre os procedimentos, mas, ao contrário, estar atenta para sua construção a todo momento. [...] Devo perceber o rastro que vou deixando enquanto danço. Devo construir, deixar-me contaminar, envolver e me modificar em um pulso que não muda nunca, se arrasta sem fim. E eu, insistindo em me arrastar pelo chão, delicada e intensamente, vasculho minhas sensações/emoções/ações e me transformo "em lesma" nessa dança que se faz em mim (SCHEYE, 2012, p.116).

Para finalizar, Agamben (2008) discute a especificidade da linguagem humana que possui, ao mesmo tempo, origens naturais e culturais. Para esta discussão, propõe a adesão de termos biológicos, endossomáticos e exossomáticos, acreditando que essas definições clarificam a descrição que segue.

A natureza diria respeito aos vínculos genéticos (endossomáticos), e a cultura, os não genéticos (exossomáticos), sendo a linguagem o mais importante deles. O homo sapiens teria essa dupla herança, que compreende uma relação complexa em relação à origem da linguagem, pois, uma vez que teria uma predisposição genética para a 
linguagem, precisa ser exposto a ela para que a possa apreender e desenvolver. São as ressonâncias geradas por esse cruzamento que caracterizam a linguagem humana, que não possui, então, oposições dualistas (língua-discurso, forma-sentido etc.) em sua estrutura, que permite, justamente, as passagens de uma propriedade a outra:

Estruturada assim sobre a diferença entre endossomático e exossomático, entre natureza e cultura, a linguagem coloca em ressonância os dois sistemas e permite sua comunicação. E é esta situação "no limite" entre duas dimensões simultaneamente contínuas e descontínuas a fazer com que a linguagem humana possa transcender a esfera puramente semiótica e adquirir (segundo a expressão de Benveniste) uma <dupla significação> . (AGAMBEN, 2008, p. 74-75).

\section{Simples considerações finais}

Como artista da dança, ainda me sinto errante frente às Peças curtas para desesquecer. Mas não tenho dúvida de que todas nós que participamos deste trabalho e criamos/materializamos nossos discursos terminamos esse processo mais maduras. Se a dança é uma linguagem e, portanto, produtora de discursos (VIEIRA, 2008), talvez, com um tanto de ousadia, seja possível entrar em consonância com Agamben (2008) e dizer que as intérpretes da Companhia Perdida tenham atravessado sua infância enquanto criadoras neste processo. O que se vê em cena é nossa história se fazendo mostrar nesta dança.

Com este estudo, espero ter conseguido construir algumas pontes para suscitar um diálogo entre dois elementos de natureza tão diversa. Traçar este paralelo era uma vontade, pois acredito que este tipo de emparelhamento possa contribuir generosamente na leitura desta obra da Companhia Perdida e no entendimento sobre seu processo de criação e, talvez, possibilite um transitar mais fluido por entre as palavras e conceitos abordados por Giorgio Agamben.

\section{Bibliografia}

AGAMBEN, Giorgio. Infância e História. Ensaio sobre a destruição da experiência. In:

AGAMBEN, Giorgio. Infância e História. Destruição da experiência e origem da história. Tradução de Henrique Burigo. Belo Horizonte: Editora UFMG, 2008, p. 19-78.

MORAES, Juliana. Lembrar de esquecer. In: MORAES, Juliana (org.). Sensorimemórias: um processo de criação da Companhia Perdida. São Paulo, 2012. Disponível em: <http://issuu. com/juliana.moraes/docs/sensorimemorias>. Acesso em 18 out. 2013.

Reflexões sobre o processo de criação de estudos para sensorimemórias. In: MORAES, Juliana (org.). Sensorimemórias: um processo de criação da Companhia Perdida. São Paulo, 2012. Disponível em: <http://issuu.com/juliana.moraes/docs/sensorimemorias>. Acesso em 18 out. 2013. 
MORESCHI, Marcelo. A memória e o lugar das sensorimemórias. In: MORAES, Juliana (org.). Sensorimemórias: um processo de criação da Companhia Perdida. São Paulo, 2012. Disponível em: <http://issuu.com/juliana.moraes/docs/sensorimemorias>. Acesso em 18 out. 2013.

ROSA, João Guimarães. Grande sertão veredas. Rio de Janeiro: Nova Fronteira, 2001.

SCHEYE, Flávia. Pelo tempo que venho arrastando. In: MORAES, Juliana (org.). Sensorimemórias: um processo de criação da Companhia Perdida. São Paulo, 2012. Disponível em: <http://issuu.com/juliana.moraes/docs/sensorimemorias>. Acesso em 18 out. 2013.

VIEIRA, Jorge de Albuquerque. Ontologia Sistêmica e Complexidade: formas de conhecimento - arte e ciência uma visão a partir da complexidade. Fortaleza: Expressão Gráfica e Editora, 2008.

Teoria do Conhecimento e Arte: formas de conhecimento - arte e ciência uma visão a partir da complexidade. Fortaleza: Expressão Gráfica e Editora, 2006. 